\title{
Transverse venous stenting for the treatment of idiopathic intracranial hypertension, or pseudotumor cerebri
}

\author{
Justin M. Cappuzzo, MD, ${ }^{1,6}$ Ryan M. Hess, BS, ${ }^{5}$ John F. Morrison, MD, ${ }^{1,6}$ \\ Jason M. Davies, MD, PhD, ${ }^{1,2,6-8}$ Kenneth V. Snyder, MD, PhD, ${ }^{1,3,6,7}$ Elad I. Levy, MD, MBA, ${ }^{1,4,6,7}$ and \\ Adnan H. Siddiqui, MD, $\mathrm{PhD}^{1,4,6-8}$
}

\begin{abstract}
Departments of ${ }^{1}$ Neurosurgery, ${ }^{2}$ Biomedical Informatics, ${ }^{3}$ Neurology, and ${ }^{4}$ Radiology, ${ }^{5} \mathrm{Jacobs}$ School of Medicine at the University at Buffalo; ${ }^{6}$ Department of Neurosurgery, Gates Vascular Institute at Kaleida Health; ${ }^{7}$ Canon Stroke and Vascular Research Center at the University at Buffalo; and ${ }^{8} \mathrm{Jacobs}$ Institute, Buffalo, New York
\end{abstract}

OBJECTIVE Idiopathic intracranial hypertension $(\mathrm{IIH})$ is a commonly occurring disease, particularly among young women of child-bearing age. The underlying pathophysiology for this disease has remained largely unclear; however, the recent literature suggests that focal outflow obstruction of the transverse sinus may be the cause. The purpose of this study was to report one group's early experience with transverse venous sinus stenting in the treatment of IIH and assess its effectiveness.

METHODS The authors performed a retrospective chart review to identify patients who had undergone stenting of an outflow-obstructed transverse venous sinus for the treatment of IIH at Gates Vascular Institute between January 2015 and November 2017. Patient demographic data of interest included age, sex, BMI, and history of smoking, hypertension, obstructive sleep apnea, hormonal contraceptive use, and acetazolamide therapy. Each patient's presenting signs and symptoms and whether those symptoms improved with treatment were reviewed. The average opening lumbar puncture (LP) pressure preprocedure, average pressure gradient across the obstructed segment prior to stenting, treatment failure rate (need for shunt placement), and mean follow-up period were calculated.

RESULTS Of the 18 patients who had undergone transverse venous stenting for IIH, $16(88.9 \%)$ were women. The mean age of all the patients was 38.3 years (median 38 years). Mean BMI was $34.2 \mathrm{~kg} / \mathrm{m}^{2}$ (median $\left.33.9 \mathrm{~kg} / \mathrm{m}^{2}\right)$. Presenting symptoms were headache (16 patients [88.9\%]), visual disturbances (13 patients [72.2\%]), papilledema (8 patients [44.4\%]), tinnitus (3 patients [16.7\%]), and auditory bruit (3 patients [16.7\%]). The mean opening LP pressure preprocedure was $35.6 \mathrm{~cm} \mathrm{H} \mathrm{H}_{2} \mathrm{O}$ (median $32 \mathrm{~cm} \mathrm{H}_{2} \mathrm{O}$ ). The mean pressure gradient measured proximally and distally to the area of focal obstruction within the transverse sinus was $16.5 \mathrm{~cm} \mathrm{H}_{2} \mathrm{O}$ (median $15 \mathrm{~cm} \mathrm{H}_{2} \mathrm{O}$ ). Postprocedurally, 14 patients $(77.8 \%)$ continued to have headaches; $6(33.3 \%)$ continued to have visual disturbances. No patients continued to have auditory bruit $(0 \%)$ or papilledema $(0 \%)$. One patient $(5.6 \%)$ had new-onset tinnitus postprocedure. Overall improvement of symptoms was noted in 16 patients (88.9\%) postprocedure, with 1 patient $(5.6 \%)$ requiring shunt placement and 2 other patients $(11.1 \%)$ requiring postprocedural LP to monitor intracranial pressure to determine candidacy for further surgical interventions to treat residual symptoms. The mean duration of follow-up was 194.2 days.

CONCLUSIONS Transverse sinus stenting is a rapidly developing technique that has shown good effectiveness and safety in the literature. Authors of the present study found that stenting a flow-obstructed transverse sinus in patients with IIH was a safe and effective way to treat the condition.

https://thejns.org/doi/abs/10.3171/2018.5.FOCUS18102

KEYWORDS stenting; idiopathic intracranial hypertension; pseudotumor; transverse sinus

I DIOPATHIC intracranial hypertension (IIH), also known as "pseudotumor cerebri" (PTC), is a medical condition characterized by an increase in intracranial pressure (ICP) without radiographic evidence of dilated ventricles or mass lesion and normal CSF content. ${ }^{13}$
The increase in ICP typically manifests as visual disturbances, papilledema and visual loss, headache, and/ or pulsatile tinnitus. Current medical treatment options include carbonic anhydrase inhibitors such as acetazolamide, furosemide, and topiramate. Procedures such as

ABBREVIATIONS ICP = intracranial pressure; IIH = idiopathic intracranial hypertension; $L P=$ lumbar puncture; PTC = pseudotumor cerebri; VSOO = venous sinus outflow obstruction.

SUBMITTED March 1, 2018. ACCEPTED May 2, 2018

INCLUDE WHEN CITING DOI: 10.3171/2018.5.FOCUS18102. 
lumbar puncture (LP) are traditionally used to decrease ICP, and additional procedures such as optic nerve sheath fenestration can be used for visual symptom relief. ${ }^{12}$

The pathophysiology of IIH is unclear. It has been linked to increased CSF production, reduced CSF absorption, and changes in vitamin A metabolism. Given the large number of patients with IIH who have venous sinus outflow obstruction (VSOO), the latter has been proposed as a possible mechanism leading to the development of the increased ICP seen in patients. ${ }^{2}$ Thus, venous sinus stenting has recently emerged as a potential treatment modality for IIH. Studies have shown that it is a safe and effective way to reduce ICP and alleviate symptoms. ${ }^{1,3,4}$

The purpose of this study was to report our early experience with transverse venous sinus stenting in the treatment of IIH and assess its effectiveness.

\section{Methods}

After obtaining institutional review board approval, we performed a retrospective review of the medical records of patients who had undergone stenting of a stenotic transverse venous sinus for the treatment of IIH at Gates Vascular Institute between January 2015 and November 2017. We reviewed our electronic medical records system to obtain basic demographic data, medical history, presenting signs and symptoms, pre-stenting procedures for IIH treatment, procedure details, and postprocedure follow-up. Medical history included height, weight, BMI, smoking status, caffeine use, comorbid medical conditions, history of bariatric surgery, and medications taken at home. Prestenting treatment for IIH was also recorded and included medical treatment such as carbonic anhydrase inhibitors, as well as interventional procedures such as LP with the corresponding opening pressure, shunt placement, and optic nerve sheath fenestration.

Recorded details of the stenting procedure included the pressure gradient measured proximally and distally to the focal area of obstruction. Postprocedural variables were also analyzed, including complications, postprocedural signs and symptoms, and whether or not a patient's symptoms had improved. Post-stent deployment pressures were not available for collection in all cases.

The duration of each patient's postprocedural course was measured by counting the number of days between the date of the procedure and the most recent clinic visit. This was defined as our follow-up period. The effectiveness of the procedure was analyzed by examining each patient's initial presenting signs and symptoms and noting if they had improved, worsened, or remained unchanged during the follow-up period. Additionally, the need for postoperative shunt placement, optic nerve sheath fenestration, or LP was recorded to determine if remaining symptoms were severe enough to warrant further intervention. Of note, all patients who received transverse sinus stents were placed on dual antiplatelet therapy with aspirin, $325 \mathrm{mg}$ daily, and clopidogrel, $75 \mathrm{mg}$ daily, for 3 months and aspirin monotherapy thereafter.

\section{Surgical Technique}

The patient is properly identified, and verbal and writ- ten consent are verified. The patient is brought to the angiography suite and positioned supine on the table. The patient is prepared and draped with exposure of the right groin area for access to the right femoral artery. Local anesthesia is administered, regardless of whether conscious sedation or general endotracheal intubation is used. The decision to administer general anesthesia or conscious sedation is a multidisciplinary process that takes into account the patient's ability to tolerate the procedure in an awake state, as well as the anesthesiologist's concerns. After the administration of sedatives, a micropuncture kit is used to access the right common femoral vein. A modified Seldinger technique is used to place an 8-Fr short sheath.

A 6-Fr catheter is typically used, such as the NeuronMax catheter (Penumbra Inc.), to introduce over the 0.035-inch Glidewire (Terumo Interventional). The entire system is advanced through the inferior vena cava into the superior vena cava and into either the right common jugular vein or the right internal jugular vein, depending on sinus dominance, based on preoperative imaging, until it reaches the level of the jugular bulb. A 3- to 4- Fr catheter such as the 3Max microcatheter (Penumbra Inc.) is used through the 6-Fr long guide to access the anterior sagittal sinus over the 0.035 -inch Glidewire. A venogram of the anterior sagittal sinus is obtained to evaluate the anatomy of the entire major venous drainage system. The contralateral sigmoid sinus and transverse sinus are similarly cannulated using a 3- to 4-Fr catheter such as the $3 \mathrm{Max}$ microcatheter. After venography, venous pressure is measured at prescribed points along the venous system to see if there is a gradient between 2 points.

Single fluoroscopic images are obtained at each measured point as the microcatheter is withdrawn, and the measurements are recorded. The contralateral venous sinuses are then accessed with the catheter by crossing the torcula with the wire. Measurements are taken from the contralateral jugular bulb backward through the sigmoid sinus up into the transverse sinus and again in the torcula and across to the ipsilateral venous sinus system.

An area of stenosis as would be expected in the arterial system is rarely identified. Instead, the venography is almost always underwhelming. The pressure gradient is key to identifying the area of obstruction. We have occasionally performed intravascular ultrasound imaging to gauge the area of obstruction and pressure gradient. ${ }^{9}$ Most lesions here appear to be mobile, potentially tissue flaps or arachnoid granulations. In the past, we have also tried balloon angioplasty and, invariably, these maneuvers result in the obstructing elements being temporarily displaced during angioplasty and then returning to their obstructed state. That is why we use primary stenting as a means to permanently displace the obstructing tissue elements.

After the pressure gradient is located, a Treasure Floppy 0.018 -inch peripheral guidewire (Asahi-Intecc Co.) is advanced with the stent, such as a Zilver $8 \times 60$-inch stent (Cook Medical), as depicted in Fig. 1. The stent is unsheathed from the 6-Fr guide catheter and deployed to cover the focal area of obstruction within the transverse sinus, as shown by the illustration in Fig. 2. Venous pressure monitoring is performed to confirm decreased pressure gradients. The wires and catheters are subsequently removed. 

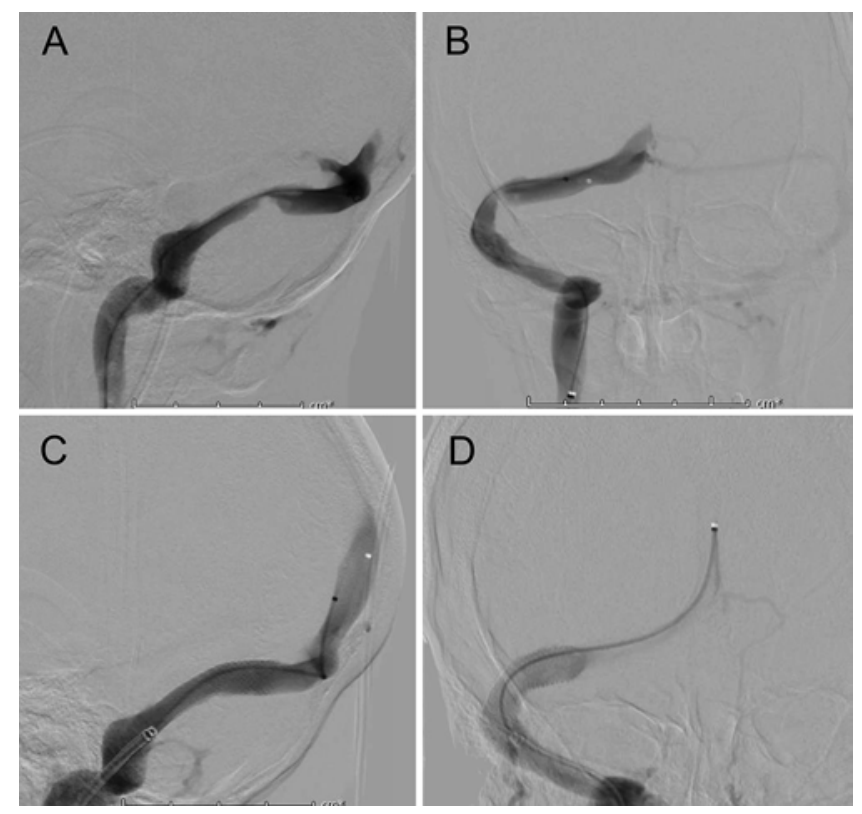

FIG. 1. Lateral (A) and coronal (B) views of the cranium demonstrating focal stenosis of the right transverse sinus prior to stent deployment. Post-stent deployment images are noted in both lateral (C) and coronal (D) planes.

The patient is evaluated for signs of hematoma, hemorrhage, or loss of distal pulses and discharged after an overnight observation period.

\section{Results}

During the study period, 19 patients were selected for transvenous stenting for IIH. One patient was excluded from analysis because of the inability to pass the catheter through the sinus and perform the procedure. Among the 18 patients who underwent the stenting procedure, the mean age was 38.3 years (median 38 years) and $16(88.9 \%)$ patients were women (Table 1). The mean BMI was $34.2 \mathrm{~kg} / \mathrm{m}^{2}$ (median $\left.33.9 \mathrm{~kg} / \mathrm{m}^{2}\right)$. Ten $(55.6 \%)$ patients had a history of smoking, $3(16.7 \%)$ had a history of hypertension, $3(16.7 \%)$ had a history of obstructive sleep apnea, and 5 (27.8\%) had a history of hormonal contraceptive use. The presenting signs and symptoms in the order of the most to the least common were as follows: headache (16 patients [88.9\%]), visual disturbances (13 patients [72.2\%]), papilledema (7 patients [38.9\%]), tinnitus (3 patients [16.7\%]), and auditory bruit (3 patients [16.7\%]). The mean opening pressure at the time of $\mathrm{LP}$ was $35.6 \mathrm{~cm} \mathrm{H}_{2} \mathrm{O}$ (median $32 \mathrm{~cm} \mathrm{H}_{2} \mathrm{O}$ ). The mean pressure gradient, measured proximally and distally to the area of focal stenosis within the transverse sinus, was 16.5 $\mathrm{cm} \mathrm{H}_{2} \mathrm{O}$ (median $15 \mathrm{~cm} \mathrm{H}_{2} \mathrm{O}$ ), which included all but one patient for whom the data were not available. The pressure across the transverse sinus on the side contralateral to the stent was only available for 11 of the 18 patients studied (Table 2). The mean pressure on the contralateral side was noted to be $19.4 \mathrm{~cm} \mathrm{H}_{2} \mathrm{O}$ (median $18.0 \mathrm{~cm} \mathrm{H}_{2} \mathrm{O}$ ).

Among the 18 patients who underwent transverse sinus stenting, $14(77.8 \%)$ continued to have headaches and 6 (33.3\%) continued to have visual disturbances postprocedurally. No patients continued to have auditory bruit or

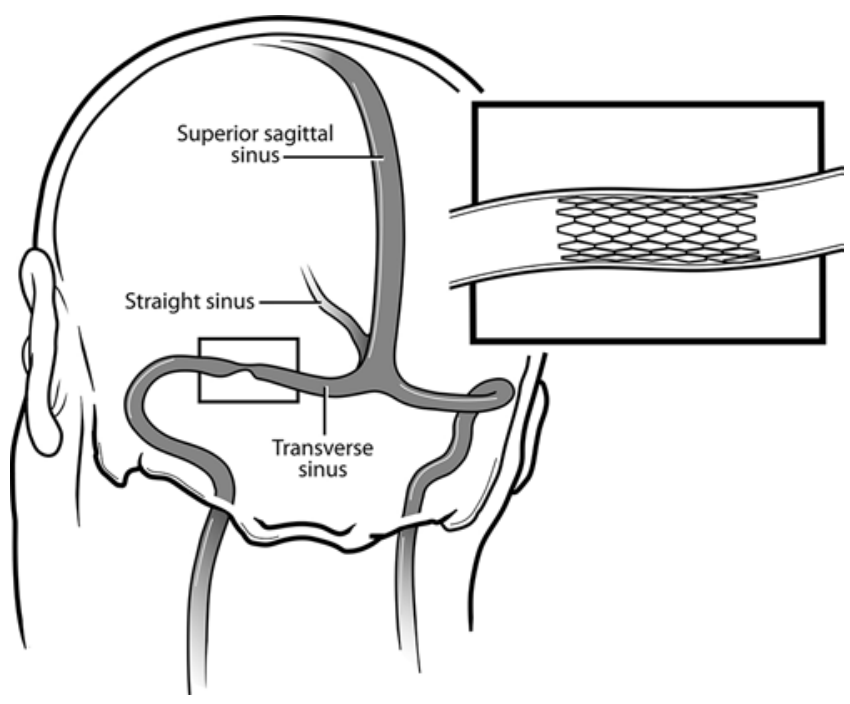

FIG. 2. Illustration of transverse sinus with stent deployment. Focal stenosis is commonly seen in patients with $\mathrm{IIH}$, which makes endovascular stent deployment a reasonable treatment for these patients. Copyright Elad I. Levy. Published with permission.

papilledema. One patient (5.6\%) had new-onset tinnitus postprocedurally. In total, $16(88.9 \%)$ patients noted improvement in their presenting symptoms or signs following transverse sinus stenting; however, 1 patient (5.6\%) eventually required shunt placement and 2 other patients (11.1\%) underwent postprocedural LP to confirm normalization of ICP to determine the need for further surgical interventions to treat residual symptoms. After undergoing stenting, one patient's opening pressure decreased from 40 to $24 \mathrm{~cm} \mathrm{H}_{2} \mathrm{O}$, and the other patient's opening pressure decreased from 27 to $16 \mathrm{~cm} \mathrm{H}_{2} \mathrm{O}$. The mean follow-up period was 194.2 days (range 22-776 days).

\section{Discussion}

Idiopathic intracranial hypertension is a relatively common disease, with most recent studies noting an incidence of approximately 0.9 cases per 100,000 individuals in the general population. ${ }^{13}$ This number increases to 19 per 100,000 individuals when narrowed to women aged 20-44 years who are $20 \%$ over their ideal weight. ${ }^{5,10}$ Although the disease primarily affects young, obese women, it can also affect men and children.11,13 Our study results were similar to those in other studies, with both a female predominance (88.9\%) and a mean age of 38.3 years (median 38 years). The mean BMI in our study was $34.2 \mathrm{~kg} / \mathrm{m}^{2}$ (median 33.9 $\mathrm{kg} / \mathrm{m}^{2}$ ), which is also consistent with the cited epidemiological data. ${ }^{5,10}$

The disease most commonly manifests with headache in upwards of $90 \%$ of cases; however, other signs and symptoms are often present. ${ }^{6,7}$ The second most common symptom is visual disturbances, which are reported in upwards of $70 \%$ of patients and are most frequently transient in nature. ${ }^{6,7}$ Tinnitus and auditory bruits, otherwise referred to as "pulsatile tinnitus," are also commonly encountered symptoms. ${ }^{13}$ In our experience, headache was the most common presenting symptom, affecting $88.9 \%$ of patients, followed by visual disturbances (72.2\%) and tinnitus (16.7\%) and au- 
TABLE 1. Characteristics of patients who underwent transverse sinus stenting for IIH

\begin{tabular}{|c|c|}
\hline Characteristic & No. $(\%)$ \\
\hline No. of patients & 18 \\
\hline \multicolumn{2}{|l|}{ Demographics } \\
\hline \multicolumn{2}{|l|}{ Age in yrs } \\
\hline Mean & 38.3 \\
\hline Median & 38 \\
\hline Female & $16(88.9)$ \\
\hline \multicolumn{2}{|l|}{$\mathrm{BMI}$ in $\mathrm{kg} / \mathrm{m}^{2}$} \\
\hline Mean & 34.2 \\
\hline Median & 33.9 \\
\hline History of smoking & $10(55.6)$ \\
\hline History of hypertension & $3(16.7)$ \\
\hline History of obstructive sleep apnea & $3(16.7)$ \\
\hline History of hormonal contraceptive use & $5(27.8)$ \\
\hline History of acetazolamide therapy & $9(50.0)$ \\
\hline \multicolumn{2}{|l|}{ Presenting signs/symptoms } \\
\hline Headache & $16(88.9)$ \\
\hline Visual disturbances & $13(72.2)$ \\
\hline Tinnitus & $3(16.7)$ \\
\hline Auditory bruit & $3(16.7)$ \\
\hline Papilledema & $8(44.4)$ \\
\hline Lumbar puncture & $17^{*}(94.4)$ \\
\hline \multicolumn{2}{|l|}{ Opening pressure in $\mathrm{cm} \mathrm{H}_{2} \mathrm{O}$} \\
\hline Mean & 35.6 \\
\hline Median & 32 \\
\hline \multicolumn{2}{|l|}{ Postprocedure signs/symptoms } \\
\hline Headache & $14(77.8)$ \\
\hline Visual disturbances & $7(38.9)$ \\
\hline Tinnitus & $1 †(5.6)$ \\
\hline Auditory bruit & $0(0)$ \\
\hline Papilledema & $0(0)$ \\
\hline \multicolumn{2}{|l|}{ Pressure gradient in $\mathrm{cm} \mathrm{H}_{2} \mathrm{O}$} \\
\hline Mean & $16.5 \ddagger$ \\
\hline Median & 15 \\
\hline Symptoms improved w/ venous stenting & $16(88.9)$ \\
\hline Required shunt placement & $1(5.6)$ \\
\hline Required postprocedural LP & $2(11.1)$ \\
\hline Mean FU in days & 194.2 \\
\hline \multicolumn{2}{|c|}{$\begin{array}{l}\text { FU = follow-up. } \\
\text { * No record of an LP performed for } 1 \text { patient who underwent a primary workup } \\
\text { at an outside hospital. } \\
\dagger \text { New-onset following venous stenting; all patients with previous tinnitus had } \\
\text { resolution of their tinnitus postprocedurally. } \\
\ddagger \text { Excluded } 1 \text { patient who did not have recorded pressure gradient value. }\end{array}$} \\
\hline
\end{tabular}

ditory bruit (16.7\%). Papilledema is also a hallmark characteristic finding in $\mathrm{IIH} ;{ }^{6,7}$ however, in our series, only 8 (44.4\%) of 18 patients were found to have papilledema.

Pseudotumor cerebri can be subclassified as either primary (otherwise known as IIH) or secondary. Idiopathic intracranial hypertension implies that no discernable cause for the elevated ICP has been found on medical workup.
Secondary PTC implies that there is an identifiable cause for the ICP elevation, ranging from VSOO to metabolic in cause. ${ }^{13}$ There is an ongoing debate about whether the cause of IIH is truly VSOO. If it is, there is a recognizable cause for the ICP elevation, and it would be classified under secondary PTC.

The diagnosis of PTC is typically made with a CSF pressure $>20-25 \mathrm{~cm} \mathrm{H}_{2} \mathrm{O}$, a normal CSF profile, no focal neurological deficits other than ICP elevation-induced cranial neuropathies such as cranial nerve VI palsy, and normal radiographs of the brain. ${ }^{8}$ Often, LP can show pressures as high as 30-40 $\mathrm{cm} \mathrm{H}_{2} \mathrm{O}$. Computed tomography venography or MR venography can also be performed to evaluate for VSOO. Typically, these noninvasive modalities fail to show abnormalities despite significant pressure gradients discovered during venous angiography. It is rare to identify a lesion on MR angiography and CT angiography that is relevant or significant during angiography or pressure measurement.

Traditional management for PTC has included carbonic anhydrase inhibitors such as acetazolamide. In medically refractory cases, more-invasive procedures such as LP and optic nerve sheath fenestration have been used. ${ }^{4}$ Given that one of the proposed pathophysiological causes of pseudotumor is VSOO, there has been a movement toward using cerebral angiography to look for stenosis in symptomatic patients. Likewise, recent advances in interventional neuroendovascular radiology have caused some to propose venous sinus stenting as a possible treatment for pseudotumor. It should be noted that angiography alone, whether arterial to evaluate venous outflow or direct through venous catheterization, is inadequate to identify lesions that appear to create a significant pressure gradient; therefore, pressures must be measured.

In 2011, Ahmed et al. published a study detailing their experience with 46 patients who underwent stenting for IIH. ${ }^{1}$ Their patient population consisted of those who remained symptomatic despite maximal medical therapy or had fulminant IIH, in addition to having either bilateral VSOO or a single hypoplastic sinus with stenosis of the contralateral side. They reported that all 46 patients experienced an immediate relief in the pressure gradient across the stenosis that correlated with a rapid reduction in IIH symptoms and papilledema. After a follow-up ranging from 2 months to 9 years, 43 patients were cured of all IIH symptoms, with the remaining 3 having residual headache without associated changes in venous pressure.

Similarly, Dinkin and Patsalides reported success in their case series of 13 patients who were refractory to or unable to tolerate medical therapy or had fulminant visual field loss and who underwent venous sinus stenting for IIH. ${ }^{4}$ They reported $100 \%$ resolution in pulse-synchronous tinnitus, diplopia, and transient visual obscuration. Headache resolved in $84.7 \%$ of the patients. Reported complications included retroperitoneal hemorrhage, transient head or pelvic pain, and a single instance of allergic reaction to contrast material.

The results of our case series followed a similar trend of symptomatic improvement following venous sinus stenting. In our study, $88.9 \%$ of patients experienced some or total improvement in their symptoms following the stent- 


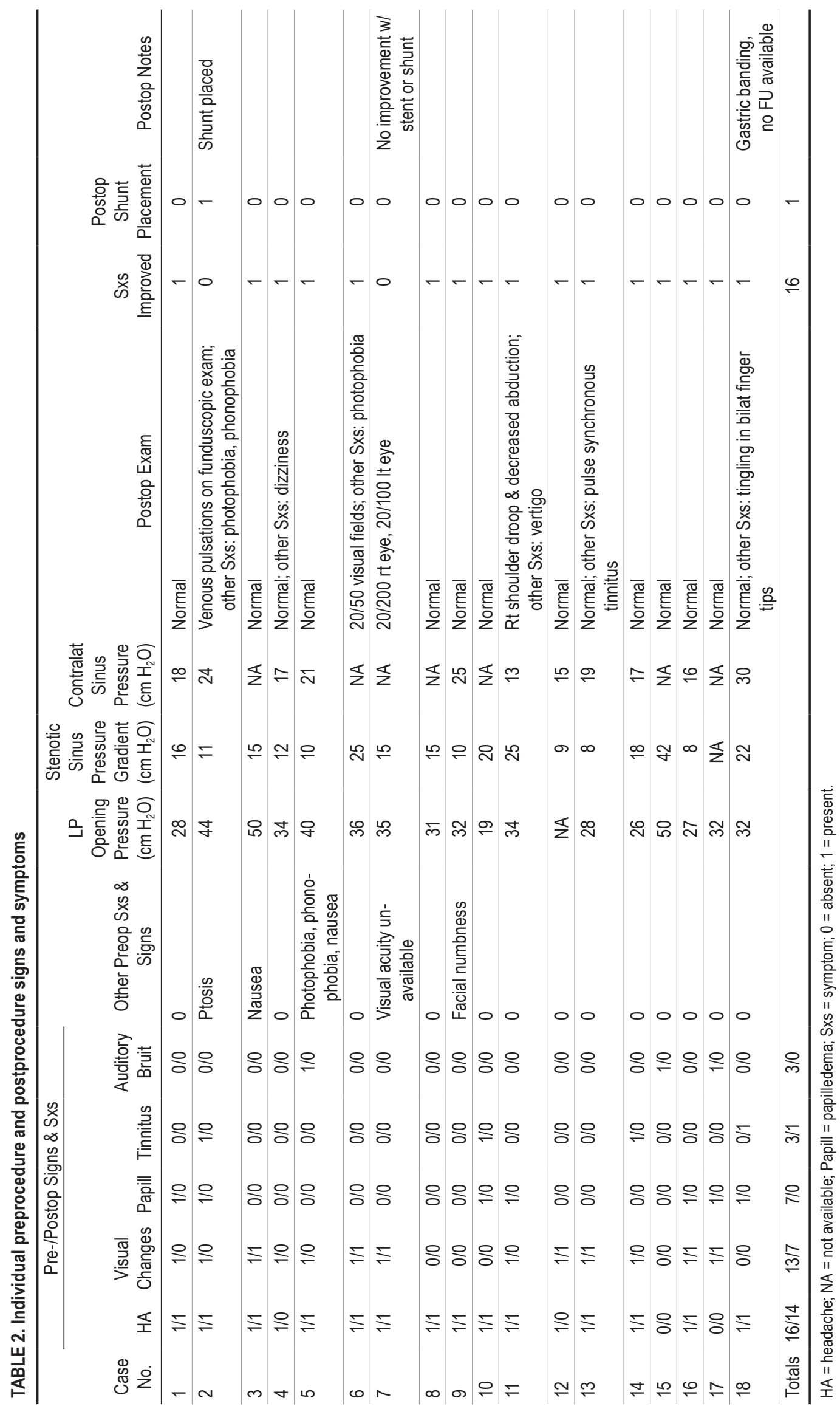




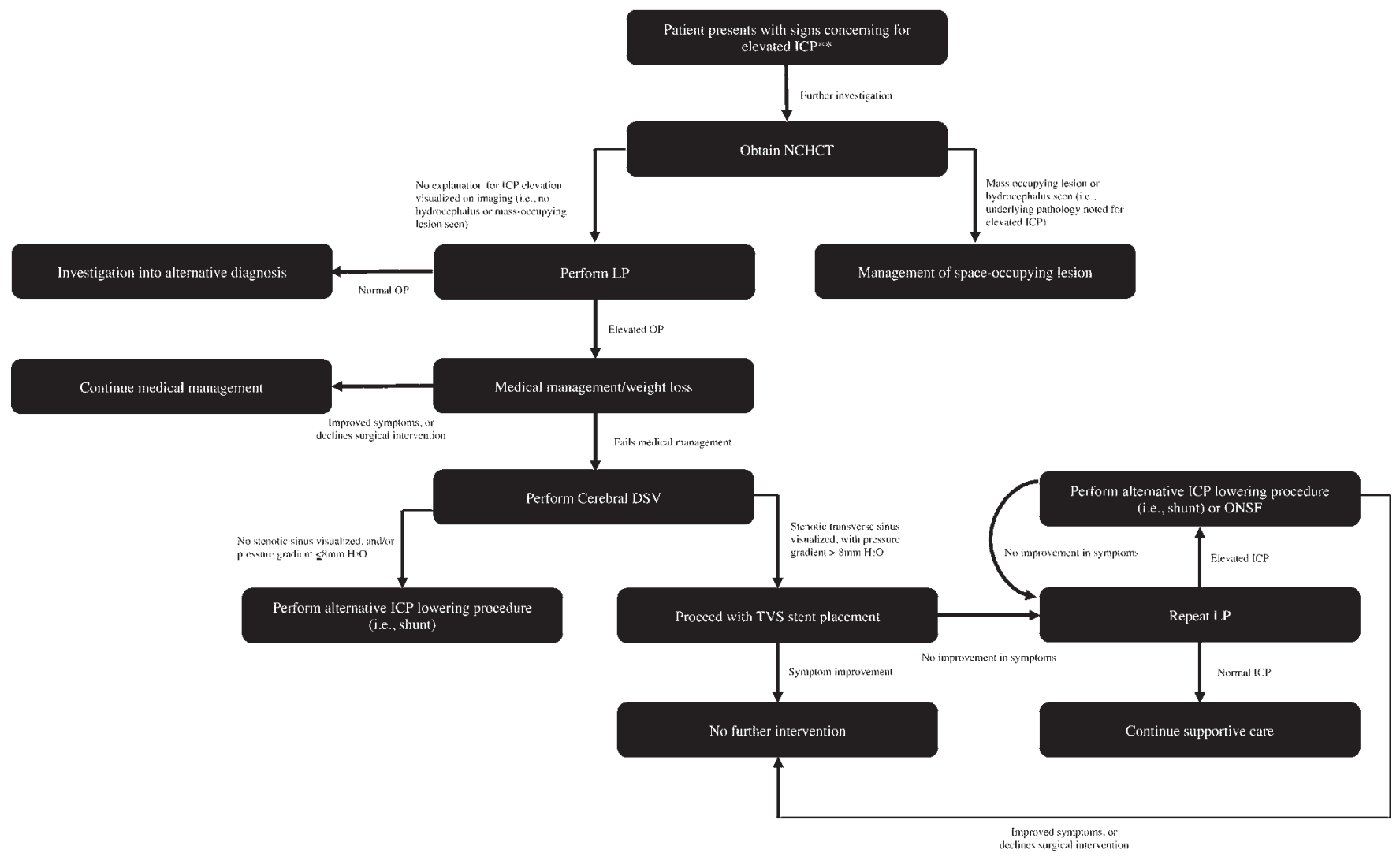

FIG. 3. Flow diagram illustrating our algorithm for the evaluation of a patient who presents with signs of elevated ICP. **For patients presenting with worsening visual symptoms, we are more likely to bypass medical management and proceed directly to digital subtraction angiography if the LP opening pressure is elevated. DSV = digital subtraction venography; NCHCT = noncontrast head CT; ONSF = optic nerve sheath fenestration; OP = opening pressure; TVS = transverse venous stent.

ing procedure, with no patient experiencing residual tinnitus, papilledema, or auditory bruit. As previously noted, one patient $(5.6 \%)$ had new-onset tinnitus postprocedure. As was the case in the studies previously mentioned, headache was the most common residual symptom in our patients; however, it was also the most common presenting symptom. One of our patients required a shunt for treatment, and the headaches improved after shunt insertion.

Postoperative LP was only performed in patients who experienced persistent symptoms following venous sinus stenting. Only 2 patients had persistent symptoms that they considered unimproved from pre-stenting. An LP was performed in these patients to determine their candidacy for further treatment. Of note, each of these patients had a significant decrease in the LP opening pressure despite a lack of improvement in their symptoms. A complete algorithm of our decision-making process is included in Fig. 3.

Our study demonstrated a level of safety similar to that in previous studies, with only 1 patient experiencing a failed procedure in which the catheter could not pass the transverse sinus and the procedure was aborted. Further investigation, including a prospective trial of this condition with long-term follow-up, is necessary to further elucidate the effectiveness of this technique.

This study is subject to the inherent limitations and biases of a retrospective analysis including recall bias and selection bias. Additionally, only those patients with focal transverse sinus stenosis noted on diagnostic angiography and a clinical diagnosis of IIH were selected to undergo transverse sinus stenting.

\section{Conclusions}

Transverse sinus stenting is a rapidly developing technique that has shown good efficacy and safety in the literature. We also found that stenting of a stenotic transverse sinus in patients with IIH was a safe and overall effective therapeutic strategy. Further investigation, including a prospective trial with long-term follow-up, is necessary to further elucidate the effectiveness of this technique.

\section{Acknowledgments}

We thank Paul H. Dressel, BFA, for preparation of the illustrations and W. Fawn Dorr, BA, and Debra J. Zimmer for editorial assistance.

\section{References}

1. Ahmed R, Friedman DI, Halmagyi GM: Stenting of the transverse sinuses in idiopathic intracranial hypertension. $\mathbf{J}$ Neuroophthalmol 31:374-380, 2011

2. Biousse V, Bruce BB, Newman NJ: Update on the pathophysiology and management of idiopathic intracranial hypertension. J Neurol Neurosurg Psychiatry 83:488-494, 2012

3. Dinkin MJ, Patsalides A: Venous sinus stenting for idiopathic 
intracranial hypertension: where are we now? Neurol Clin 35:59-81, 2017

4. Dinkin MJ, Patsalides A: Venous sinus stenting in idiopathic intracranial hypertension: results of a prospective trial. $\mathbf{J}$ Neuroophthalmol 37:113-121, 2017

5. Durcan FJ, Corbett JJ, Wall M: The incidence of pseudotumor cerebri. Population studies in Iowa and Louisiana. Arch Neurol 45:875-877, 1988

6. Friedman DI, Jacobson DM: Idiopathic intracranial hypertension. J Neuroophthalmol 24:138-145, 2004

7. Friedman DI, Liu GT, Digre KB: Revised diagnostic criteria for the pseudotumor cerebri syndrome in adults and children. Neurology 81:1159-1165, 2013

8. Greenberg MS: Pseudotumor cerebri and empty sella syndrome, in Handbook of Neurosurgery, ed 8. New York: Thieme, 2016, pp 766-774

9. Mokin M, Lopes DK, Binning MJ, Veznedaroglu E, Liebman KM, Arthur AS, et al: Endovascular treatment of cerebral venous thrombosis: contemporary multicenter experience. Interv Neuroradiol 21:520-526, 2015

10. Radhakrishnan K, Ahlskog JE, Cross SA, Kurland LT, O'Fallon WM: Idiopathic intracranial hypertension (pseudotumor cerebri). Descriptive epidemiology in Rochester, Minn, 1976 to 1990. Arch Neurol 50:78-80, 1993

11. Rangwala LM, Liu GT: Pediatric idiopathic intracranial hypertension. Surv Ophthalmol 52:597-617, 2007

12. Thurtell MJ, Wall M: Idiopathic intracranial hypertension (pseudotumor cerebri): recognition, treatment, and ongoing management. Curr Treat Options Neurol 15:1-12, 2013

13. Winn HR: Pseudotumor cerebri, in Youmans and Winn Neurological Surgery, ed 7. Philadelphia: Elsevier, 2016, pp 1352-1364

\section{Disclosures}

Dr. Davies has been a consultant for Neurotrauma Sciences, has served on the Data Safety and Monitoring Board for StrokeNet, and has been a KL-2 scholar. Dr. Morrison has received grants from NVIDIA Corp. and Google. Dr. Levy has shareholder/ ownership interests in Intratech Medical Ltd., NeXtGen Biologics, Rapid Medical, Claret Medical, Cognition Medical, Rebound Thera, StimMed, and Three Rivers Medical Inc.; has been a consultant for Pulsar Vascular; has been on the advisory board for Stryker, NeXtGen Biologics, MEDX, Cognition Medical, and Endostream Medical; is the national principle investigator for SWIFT Prime and SWIFT Direct Trials; and is the site principle investigator for Microvention for the CONFIDENCE study. Dr. Siddiqui has financial interest/investor/stock options/ownership in Amnis Therapeutics, Apama Medical, BlinkTBI Inc., Buffalo Technology Partners Inc., Cardinal Health, Cerebrotech Medical Systems Inc., Cognition Medical, International Medical Distribution Partners, Rebound Therapeutics Corp., Synchron, Three Rivers Medical Inc., Viseon Spine Inc.; and has been a consultant for Amnis Therapeutics Ltd, Boston Scientific, Canon Medical Systems USA Inc., Cerenovus, Claret Medical, Corindus Inc., Endostream Medical Ltd., Guidepoint Global Consulting, Imperative Care, Integra, Medtronic, MicroVention, Penumbra, Rapid Medical, Rebound Therapeutics Corp., Silk Road Medical, StimMed, Stryker, Three Rivers Medical Inc., VasSol, and W.L. Gore \& Associates. Dr. Snyder has been a consultant and teacher for Canon Medical Systems Corp., Penumbra Inc., Medtronic, and Jacobs Institute; and is the founder of Neurovascular Diagnostics Inc.

\section{Author Contributions}

Conception and design: Hess. Acquisition of data: all authors. Analysis and interpretation of data: all authors. Drafting the article: Cappuzzo, Hess. Critically revising the article: all authors. Reviewed submitted version of manuscript: all authors.

\section{Correspondence}

Adnan H. Siddiqui: University at Buffalo, Buffalo, NY. asiddiqui@ubns.com. 